\title{
SURVEILLANCE OF APPENDICECTOMY SPECIMEN WITH HISTOMORPHOLOGICAL EVALUATION
}

\author{
PRATIMA BAISAKH ${ }^{1 *}$, MANAS RANJAN BAISAKH ${ }^{2}$, PRAFULLA KUMAR CHINARA ${ }^{1}$, MAHESH CHANDRA SAHU ${ }^{3}$
}

${ }^{1}$ Department of Anatomy, IMS and SUM Hospital, Siksha 'O' Anusandhan Deemed to be University, K8, Kalinga Nagar, Bhubaneswar 751 003, Odisha, India. ${ }^{2}$ Department of Pathology, Apollo Hospitals, Bhubaneswar, Odisha, India. ${ }^{3}$ Directorate of Medical Research, IMS and SUM Hospital, Siksha '0’ Anusandhan Deemed to be University, Bhubaneswar - 751 003, 0disha, India. Email: drpbaisakh@gmail.com Received: 23 Feburary 2018, Revised and Accepted: 29 March 2018

ABSTRACT

Objective: Appendicectomy is the gold standard treatment in acute appendicitis, and in each case, a specimen should be evaluated thoroughly by a histopathologist to confirm the diagnosis and any unknown pathology. The present study aims to find out age and gender prevalence of appendicitis in a tertiary care hospital in Eastern India and various histological changes in the appendix in routine appendicectomy specimen undergoing surgery for appendicitis.

Methods: A total of 780 appendicectomy specimens were studied for acute appendicitis for 2 years. Gender prevalence and age-wise incidence of appendicitis were analyzed statistically. Sections were taken from different parts of formalin-fixed appendix specimen. A thorough histological examination was done to confirm acute appendicitis and to detect any incidental unusual histological changes.

Results: Of 780 cases, 343 (44\%) were male and 437 (56\%) were female. Females are more in number than males (p<0.001). The incidence was more common in the age group of 21-30 years (50.7\%). Histological findings revealed normal vermiform appendix in 60 (7.7\%), lymphoid hyperplasia in $75(9.6 \%)$ cases, acute appendicitis and periappendicitis in $471(60 \%)$ and $110(14 \%)$ cases, respectively. Gangrenous appendicitis was found in $56(7 \%)$ cases. Unexpected findings were reported in $8(1.02 \%)$ cases, of which Enterobius vermicularis 2 (0.25\%) cases, endometriosis 2 (0.25\%) cases, mucocele $1(0.12 \%)$ case, and carcinoid in $3(0.4 \%)$ cases.

Conclusions: Apart from intraoperative examination, a routine histological study of biopsy specimen reveals at times rare pathological changes which has some impact on clinical co-relation and patient management and might help to avoid any lethal complications.

Keywords: Appendicitis, Appendicectomy, Mucocele, Endometriosis.

(c) 2018 The Authors. Published by Innovare Academic Sciences Pvt Ltd. This is an open access article under the CC BY license (http://creativecommons. org/licenses/by/4. 0/) DOI: http://dx.doi.org/10.22159/ajpcr.2018.v11i7.25432

\section{INTRODUCTION}

The vermiform appendix is a tubular structure attached to the posteromedial wall of cecum at the confluence of all taenia coli about $2 \mathrm{~cm}$ below ileocecal valve [1]. The different anatomical positions depending on the direction of its tip are retrocecal (60\%), pelvic (30\%), paracecal, pre-ileal, post-ileal, and promonteric type [1]. This variable position may affect the clinical manifestations of appendicitis [2]. Histologically, it consists of innermost lining epithelium, lamina propria studded with lymphatic nodules extending to submucosa, muscularis externa, and serosa [3]. Appendicitis is the most common cause of acute abdomen. The exact etiopathogenesis of appendicitis is not established till now. It may be due to obstruction of lumen leading to distension and impaired circulation and If the cause obstruction remain untreated it leads to perforation of appendix and peritonitis. Appendicitis is more common in males than females with a ratio of 1.7:1. Early appendicectomy in suspected appendicitis leads to decreased morbidity, but histological evaluation shows no inflammation in $9-40 \%$ of cases $[4,5]$. In conventional practice, histopathology of appendicectomy specimens used to depend on surgeons view [6]. Many samples are not sent for histology unless any gross abnormality is detected by the surgeon [6]. However, many studies found incidental abnormal findings after histological evaluation in which patients need further treatment and follow-up [7-9]. $<50 \%$ of appendicular tumors are identified intraoperatively, and the rest are diagnosed after biopsy evaluation incidentally [10]. It was also reported that normal looking appendicectomy specimens show inflammatory changes after histologic study suggesting some other hidden condition [11]. Therefore, the present study was carried out to find different pathological changes in the routine appendicectomy specimen in suspected appendicitis cases for a proper diagnosis and management.

\section{METHODS}

This prospective study was carried out in a tertiary care hospital and it is approved by the Institutional Ethics committee. Appendix specimen was collected from 780 patients undergoing appendicectomy with a presumptive diagnosis of acute appendicitis from January 2014 to January 2016. Gender prevalence and age-wise incidence were analyzed. All specimens were formalin fixed, and macroscopic examination was done. Sections were taken from different parts of formalin-fixed specimens such as tip, body, and base and stained with hematoxylin and eosin stain and seen under the light microscope. Findings were recorded as acute appendicitis along with associated periappendicitis, recurrent appendicitis, gangrenous appendicitis, follicular hyperplasia, and unusual incidental findings. Statistical analysis was performed using the latest version of SPSS software when required.

\section{RESULT}

Of 780 patients, males were 343 (44\%) and females were 437 (56\%) in number. The number of females significantly outnumbered the males $(p<0.001)$. The mean age of the patients was 30 years varying from 10 years to 80 years (Table 1). The number of abnormal pathological findings of males and females was 5 and 3 , respectively. It was revealed with $\lambda^{2}$ that there is no significant difference found with respect to gender in abnormal cases. After histologic evaluation, normal appendix was found in 60 cases $(7.7 \%)$ without any pathological change in the wall. Features of acute appendicitis were found in 471 cases $(60 \%)$ 
(Fig. 1a). Lymphoid hyperplasia was reported in 75 (9.6\%) cases (Fig. 1b). Associated findings along with acute appendicitis such as gangrenous appendicitis and peri-appendicitis (Fig. 1c) were found in $56(7 \%)$ and $110(14 \%)$ cases, respectively (Table 2). The incidental abnormal findings reported in $8(1.02 \%)$ cases. They were mucocele (Fig. 2a) in one case, endometriosis (Fig. 2b) in two cases, Enterobius vermicularis (Fig. 2c) in two cases, and carcinoid (Fig. 2d) in three cases (Table 3). Maximum cases were in the age range of 21-30 years (50.7\%) followed by $31-40$ years (25.6\%) (Table 4 ).

\section{DISCUSSION}

Appendicitis is the most common cause of acute abdomen in any age group. Diagnosis of appendicitis is usually based on periumbilical pain, pain, and rigidity in the right lower quadrant of abdomen along with fever and vomiting [11]. The main cause of appendicitis is the lumen obstruction by a fecalith that leads to increase mucus secretion and lymphoid hyperplasia. This causes further obstruction and if left untreated leads to perforation, gangrene, and abscess formation. Appendicitis is very rare at two extremes of age, i.e. in infants due to wider lumen and at old age due to the obliteration of the lumen [12]. The maximum incidence of appendicitis occurs in the second decade; thereafter, the disease incidence declines with age $[13,14]$. However, in the present study, the mean age of presentation is 30 years and maximum is in the age range of 21 years-30 years [50.7\%], followed by 31 years -40 years [25.6\%]. This may be due to changing food habit and intake of unhealthy food in this group. In our study, females were significantly more in number than males which coincide with a study by Naveen et al. on South Indian population [15]. A study by Noudeh et al. in Taiwan population reported more cases of males than females [16]. A similar study by Al-Omran et al. showed that males are affected more in number than females and in the age range of 10-19 years in Canada [17]. This may reflect the regional variation of incidence of appendicitis. Histological examination of appendicectomy specimen carried out for two purposes, first to confirm the diagnosis of appendicitis and second to exclude any unusual findings. Both the things affect further management. In the present study, normal appendix was found in 60 cases (7.7\%). Lymphoid hyperplasia is another cause obstruction and acute inflammation. We found only lymphoid hyperplasia in 75 (9.6\%) cases. After histologic examination, some

Table 1: Number of patients of appendicitis with respect to gender

\begin{tabular}{lll}
\hline Gender & Total number of patients (\%) & Abnormal finding \\
\hline Males & $343(44)$ & 5 \\
Females & $437(56)$ & 3 \\
Total & $780(100)$ & 8 \\
\hline
\end{tabular}

Table 2: Histological findings of appendicitis patients

\begin{tabular}{ll}
\hline Histological findings & n (\%) \\
\hline Normal & $60(7.7)$ \\
Acute appendicitis & $471(60)$ \\
Periappendicitis & $110(14)$ \\
Lymphoid hyperplasia & $75(9.6)$ \\
Gangrenous appendicitis & $56(7)$ \\
Abnormal findings & $8(1.7)$ \\
Total & $780(100)$ \\
\hline
\end{tabular}

Table 3: Details of abnormal findings from histological evaluation $(n=780)$

\begin{tabular}{lll}
\hline E. vermicularis & 2 & $0.25 \%$ \\
Endometriosis & 2 & $0.25 \%$ \\
Mucocele & 1 & $0.125 \%$ \\
Carcinoid & 3 & $0.4 \%$ \\
\hline
\end{tabular}

E. vermicularis: Enterobius vermicularis unusual findings were reported. Enterobius vermicularis was found in $0.25 \%$ of cases. Previous studies show E. vermicularis in $0.18-4.1 \%$ of cases and rarely present with features of acute appendicitis [18]. Mucocele is a very rare condition of appendix. There are four histologic types of appendiceal mucocele: Retention cyst, mucosal hyperplasia, mucinous cystadenoma, and mucinous cystadenocarcinoma [19]. Appendectomy is the standard of care for mucinous cystadenoma, whereas a cystadenocarcinoma requires a right hemicolectomy. In the present study, cystadenocarcinoma found in one case $(0.125 \%)$. This incidence is very less in comparison to a study by Jones et al. where they reported $0.25 \%$ of cases [20]. Due to the high association of mucinous neoplasm with colon and ovarian malignancy, followup computed tomography (CT), US, and colonoscopy examinations must be performed during the post-operative period. Carcinoid is another clinical condition that most commonly affects appendix and could not be diagnosed intraoperatively. We found three cases $(0.4 \%)$ of carcinoid which was very less than the study by Jones et al. in the UK. However, a review by Arife Polat Duzgun showed only $0.1 \%$ of

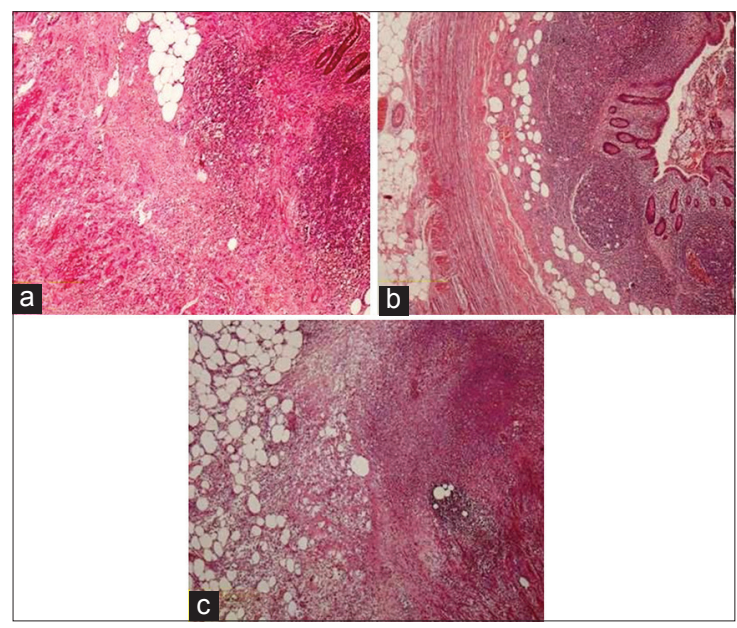

Fig. 1: (a) Acute appendicitis - appendix with edematous wal and dense infiltration by inflammatory cells. (b) Follicular hyperplasia - Markedly hyperplastic lymphoid follicle,

(c) Gangrenous appendicitis - Gangrenous wall with a large area of necrosis and periappendicitis

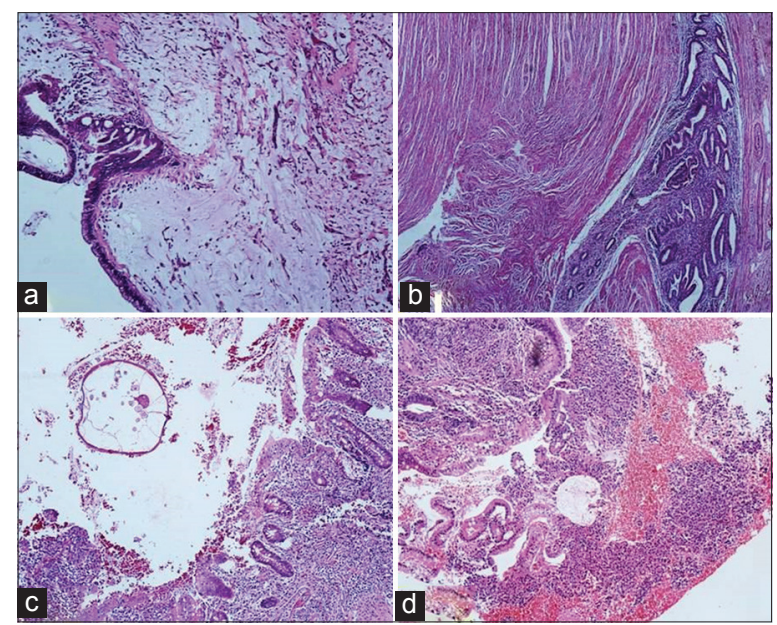

Fig. 2: (a) Mucinous carcinoma appendix - Pool of mucin with occasional floating tumor cells in the lamina propria and muscle layer. (b) Endometriosis in appendix - Endometrial gland and stroma in the muscularis propria. (c) Enterobius vermicularis - Lumen showing cross-sectional parasite.

(d) Appendicular carcinoid - Seeds of neuroendocrine tumor cells having uniform nuclei and eosinophilic cytoplasm 
Table 4: Abnormal findings from histological evaluation with respect to age

\begin{tabular}{|c|c|c|c|c|c|}
\hline Age group (years) & Findings consistent with appendicitis (\%) & E. vermicularis & Endometriosis & Mucocele & Carcinoid \\
\hline $10-20$ & $55(7.05)$ & 0 & 0 & 0 & 0 \\
\hline $21-30$ & $396(50.7)$ & 1 & 1 & 0 & 0 \\
\hline $31-40$ & $200(25.6)$ & 0 & 1 & 1 & 2 \\
\hline $41-50$ & $62(7.9)$ & 0 & 0 & 0 & 1 \\
\hline $51-60$ & $39(5)$ & 1 & 0 & 0 & 0 \\
\hline $61-70$ & $18(2.3)$ & 0 & 0 & 0 & 0 \\
\hline $71-80$ & $10(1.3)$ & 0 & 0 & 0 & 0 \\
\hline
\end{tabular}

E. vermicularis: Enterobius vermicularis

cases of carcinoid in appendicectomy specimen for appendicitis [7]. Carcinoids are the most common benign tumor of appendix, and it may be associated with carcinoid of other sites of the intestine. Carcinoid of appendix usually affects the tip, so meticulous sampling during biopsy is required. Appendiceal endometriosis is another incidental finding that is detected after histological evaluation. According to Akbulut et al., intestinal endometriosis occurs in only about $10 \%$ of women with endometriosis and most common sites are rectum and sigmoid colon but rarely in appendix [19]. Appendiceal endometriosis is $2.8 \%$ of endometriosis affecting females [21]. It can occur on women of both fertility age group and postmenopausal age group [22]. We found two cases of endometriosis (0.25\%) among our study population in the women of fertile age group. Appendiceal endometriosis is usually asymptomatic but sometimes presents as appendicitis, perforation, and intussusception $[19,23,24]$. In the present study, both of them manifest as acute appendicitis and after histopathology study advised for hormone therapy.

\section{CONCLUSION}

Appendicectomy is the gold standard of therapy in all types of appendicitis cases. The present study on eastern India population highlighted the sex prevalence and age distribution of the cases. It was important to find post-operative histopathological examination and requires awareness and understanding of different usual and rare entities of the organ which affects further management.

\section{AUTHOUR'S CONTRIBUTION}

All the authours contributed equally.

\section{CONFLICTS OF INTEREST}

There are no conflicts of interest.

\section{REFERENCES}

1. Buschard K, Kjaeldfaard A. Investigation and analysis of the position, fixation, length and embryology of the vermiform appendix. Acta Chir Scand 1973;139:293-8.

2. Guidry SP, Poole GV. The anatomy of appendicitis. Am Surg 1994;60:68-71.

3. O'Connell PR. The vermiform appendix. In: Williams NS, Bulstrode CJ, O'Connell PR, editors. Bailey and Love's Short Practice of Surgery. $25^{\text {th }}$ ed. London (UK): Hodder Arnold; 2008. p. 1204-18.

4. Baigrie RJ, Dehn TC, Fowler SM, Dunn DC. Analysis of 8651 appendicectomies in England and Wales during 1992. Br J Surg 1995;82:933.

5. Hale DA, Jaques DP, Molloy M, Pearl RH, Schutt DC, d'Avis JC. Appendectomy: Improving care through quality improvement. Arch
Surg 1997;132:153-7.

6. Matthyssens LE, Ziol M, Barrat C, Champault GG. Routine surgical pathology in general surgery. Br J Surg 2006;93:362-8.

7. Duzgun AP, Moran M, Uzun S, Ozmen M, Ozer VM, Seckin S, et al. Unusual findings in appendicectomy specimens: Evaluation of 2458 cases and review of the literature. Indian J Surg 2004;66:221-6.

8. Nemeth L, Reen DJ, O'Briain D, McDermott M, Pui P. Evidence of an inflammatory pathologic condition in "Normal" appendices following emergency appendectomy. Arch Path Lab Med 2001;125:759-64.

9. Modlin IM, Sandor A. An analysis of 8305 cases of carcinoid tumours. Cancer 1997;79:813-29.

10. Connor SJ, Hanna GB, Frizell FA. Appendiceal tumors. Dis Colon Rectum 1998;41:75-80.

11. Birnbaum BA, Wilson SR. Appendicitis at the millennium. Radiology 2000;215:337-348.

12. Vishram S. Clinical and Surgical Anatomy. $2^{\text {nd }}$ ed. New Delhi: Elsevier; 2007. p. 178-9.

13. Addiss DG, Shaffer N, Fowler BS, Tauxe RV. The epidemiology of appendicitis and appendectomy in the United States. Am J Epidemiol 1990;132:910-25.

14. Primatesta P, Goldacre MJ. Appendicectomy for acute appendicitis and for other conditions: An epidemiological study. Int J Epidemiol 1994;23:155-60.

15. Naveen K, Sareesh NN, Satheesha BN, Murlimanju BV, Suhani S, Mamatha $\mathrm{H}$, et al. Appendicitis and appendectomy: A retrospective survey in south Indian population. J Surg Acad 2013;3:10-3.

16. Noudeh YJ, Sadigh N, Ahmadnia AY. Epidemiologic features, seasonal variations and false positive rate of acute appendicitis in Shahr-e-Rey, Tehran. Int J Surg 2007;5:95-8.

17. Al-Omran M, Mamdani M, McLeod RS. Epidemiologic features of acute appendicitis in Ontario, Canada. Can J Surg 2003;46:263-8.

18. Bobekir AR, Devi N. Analysis of pathology of 405 appendectomies. East Afr Med J 1990;67:599-602.

19. Akbulut S, Tas M, Sogutcu N, Arikanoglu Z, Basbug M, Ulku A, et al. Unusual histopathological findings in appendectomy specimens: A retrospective analysis and literature review. World J Gastroenterol 2011;17:1961-70.

20. Jones AE, Phillips AW, Jarvis JR, Sargen K. The value of routine histopathological examination of appendicectomy specimens. BMC Surg 2007;7:17

21. Gustofson RL, Kim N, Liu S, Stratton P. Endometriosis and the appendix: A case series and comprehensive review of the literature. Fertil Steril 2006;86:298-303.

22. Stenchever MA, Droegemueller W, Herbst AL. Comprehensive Gynecology. $4^{\text {th }}$ ed. St. Louis: Mosby; 2001.

23. Nagapuri S. Market research on usage of antibiotics in serious infections. Int J Pharm Pharm Sci 2014;6:371-4.

24. Sodimbaku V, Pujari L. Urolithiasis-an updated review over genetics, pathophysiology and its clinical management. Int J Pharm Pharm Sci 2014;6:23-31. 